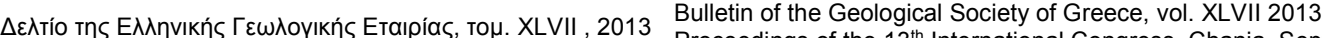
Proceedings of the $13^{\text {th }}$ International Congress, Chania, Sept.

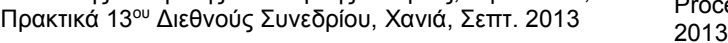

\title{
SIMULATION OF UNDERGROUND COAL GASIFICATION PROCESS IN A BULGARIAN COAL FIELD
}

\author{
Koukouzas N. ${ }^{1}$, Katsimpardi I. ${ }^{1}$ and Merachev D. ${ }^{2}$ \\ ${ }^{I}$ Chemical Processes and Energy Resources Institute /The Centre for Research and Technology \\ Hellas,koukouzas@certh.gr,katsimpardi@certh.gr \\ ${ }^{2}$ Overgas, 5 Philip Kutev st. 1407 Sofia, Bulgaria
}

\begin{abstract}
The sustainable and environmentally friendly energy production has been a major issue of the world energy sector in recent years. Coal is a major fossil fuel that provides approximately $25 \%$ of the total energy demand worldwide; coal reserves still remain significant, although in several cases its exploitation trends to be economically marginal. Underground Coal Gasification (UCG) has been identified as a technology which can bridge the gap between energy production and environmental and financial sustainability. Several UCG trials have taken place, although, there are still questions relative to their safety, performance and applicability. To that direction, modelling can prove to be a very effective and practical tool for the prediction of the project performance and the reduction of the risk involved. UCG is a complex process which incorporates mechanical and chemical processes thus modelling is complex since it demands coupling the aforementioned processes. The current study aims at investigating the applicability of the UCG process in a Bulgarian coal site through $2 D$ modelling. The proposed approach uses FLAC software as a modelling tool and attempts to combine thermal and mechanical effects during the gasification process. Several simulation runs have taken place in an attempt to quantify the effect of the different mechanical and thermal properties of the surrounding rocks to the UCG process, the environmental effects and the stability of the geological formations.
\end{abstract}

Key words: UCG, Underground Coal Gasification, Geomechanical modelling.

\section{$\Pi \varepsilon \rho i ́ \lambda \eta \psi \eta$}

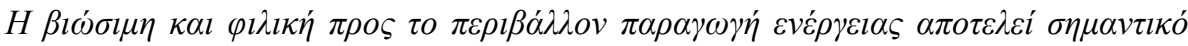

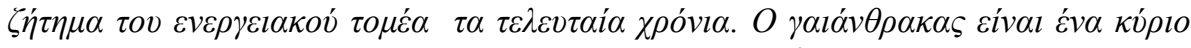

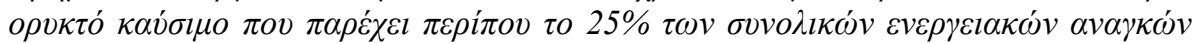

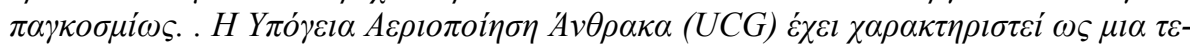

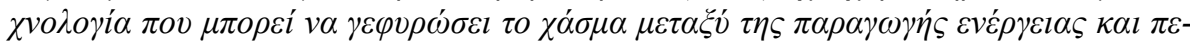

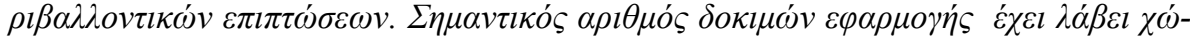

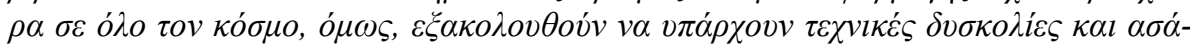

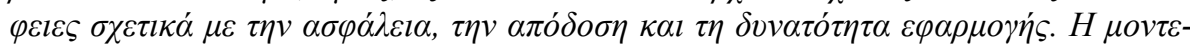

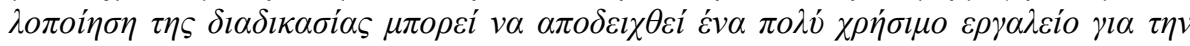

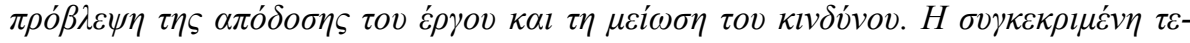

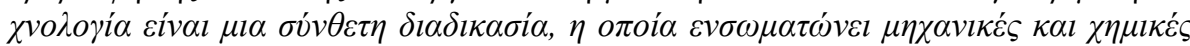

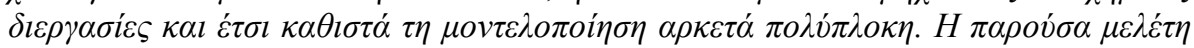

$\underline{\text { XLVII, No } 3-2090}$ 


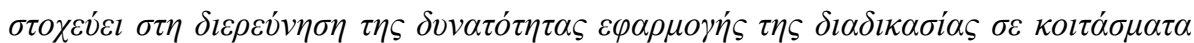

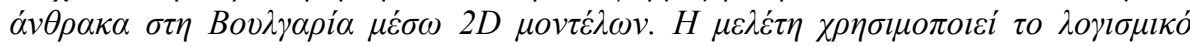

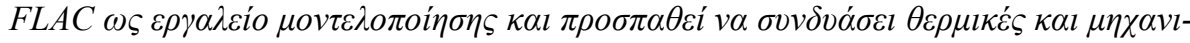

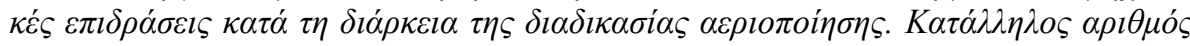

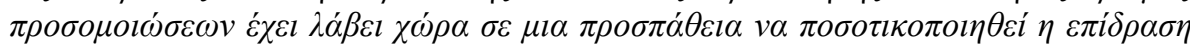

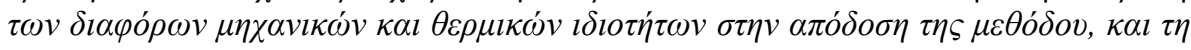

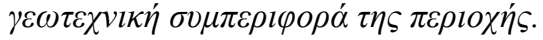

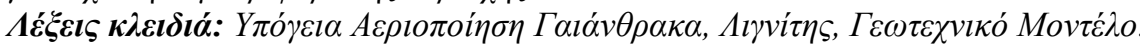

\section{Introduction}

Coal is one of the most important sources of energy worldwide. It is used to produce coke for steel production plants, it can be burned directly as a fuel to generate heat or electricity, and finally it can be gasified (World Coal Institute, 2011). Normally the gasification process takes place in large reaction vessels on surface, but an alternative and more environmentally friendly method is Underground Coal Gasification (UCG), during which coal is being converted into gaseous products in-situ. UCG presents a number of advantages such as no ash production, no need of coal handling on surface, no need for transportation of coal, minimum need for mining and land reclamation processes. The overall surface disruption due to the UCG process is minimal, as the process takes place in depth, $\mathrm{CO}_{2}$ gas produced can be captured and sequestrated thus reducing the amount of $\mathrm{CO}_{2}$ emission up to 0.4 tonnes/MWh which is half of the amount released in surface gasification process (Burton, 2006).

During the UCG process, initially, two wells, injection and production, are drilled vertically from the surface to the coal seam at a certain distance, and a permeable channel link is created between them. To gasify the coal, a mixture of air/oxygen and steam is introduced into the coal seam through the injection well. The product gas travels through the cavity and elutes from the production well through the cavity (Chappell et all, 1983). The generated product gas is collected at the surface and sent for end use after being cleaned. The quality of the product gas is influenced by several parameters such as the pressure inside the coal seam, coal properties, feed conditions, kinetics, and heat and mass transport within the coal seam. As gasification proceeds, an underground cavity is formed. The volume of the cavity increases progressively with coal consumption and thermo mechanical spalling, from the roof. Numerical modelling has been used in the past to investigate a variety of problems in underground mining and tunnelling thus making UCG and cavity formation a process which can be investigated through geomechanical modelling (Harloff, 1983). The finite difference analysis software FLAC has been utilised for this purpose. The model includes the detailed lithologic structure of a section of the Dobrudzha Coal Deposit (DCD) site. A vertical geological fault is also incorporated in the geometry of the model. The gasification process is simulated using small increments of heat flux to represent its duration.

\section{The Dobrudzha Coal Deposit}

The Dobrudzha Coal Deposit is situated in a geologically complex area with several geological layers and numerous faults. Figure 1 presents the geological West-East cross section at Gurkovo local area at DCD site. The specific area in the blue box has been selected as it includes the majority of geological formations in the DCD area, a fault crossing; and various layers of coal seams which are located in the carboniferous layer. Coal seam P3 has been selected for the purposes of modelling. The coal seam P3 is approximately $5 \mathrm{~m}$ thick. The ignition point and the production well has been set at a distance of $300 \mathrm{~m}$ and the $100 \mathrm{~m}$ from the right hand section accordingly. The model includes the detailed lithologic information and material properties to account for gasification cavity growth as well as the reaction of the geologic fault.

XLVII, No 3 - 2091 


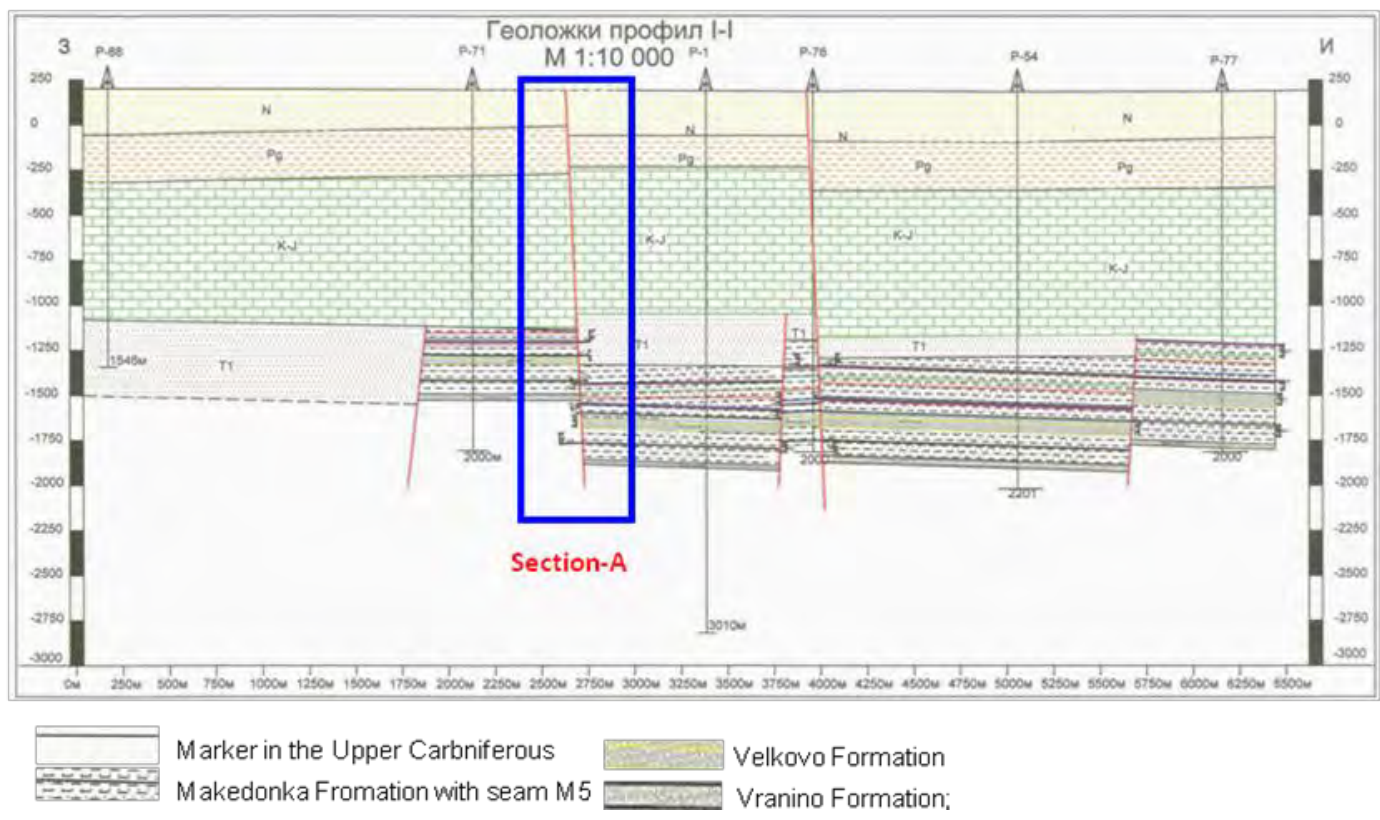

Figure 1 - Geological west-east cross section, Gurkovo local area at DCD (Overgas, 2011).

\section{Basic FLAC Model of the DCD Area}

In this initial stage of the modelling process, the construction of a simplified model that simulates the thermal and mechanical processes of Underground Coal Gasification was attempted. The main objective of this modelling stage is to achieve the thermal- mechanical coupling, and investigate the effect of temperature to the cavity formation.

Taking into consideration, the fact that the geology of the specific area is extremely complex, a simplified model was first constructed in order to get a preliminary idea of how the software works and check the thermal mechanical coupling feature. In the next stage a more enhanced model with additional geological features incorporated will be used, aiming at giving more precise results in what concerns the determination of ground deformation and cavity development.

\subsection{Model Construction}

A simple geometry (Figure 2) has been used for this model which consists of a 10-meter coal layer in a depth of 100 meter (depth of roof). The gasification takes place in the middle of the coal seam to a length of 30 meters and is surrounded by rock layers on both sides. The model expands 30 meters to both side directions and 45 meters below the coal seam so that localization effect is avoided. The UCG process has been divided in three stages for monitoring purposes. In that way the cavity development and thermal distribution into the rock during the UCG process can be monitored in a precise way.

- Boundary conditions

Prescribed-displacement boundaries have been used in this model, and are applied by prescribing the boundary's velocity. So, in this case, 151 roller supports have been used to fix x-direction displacement of models right and left edge and 101 rollers to fix y-direction displacement of the bottom of model. 


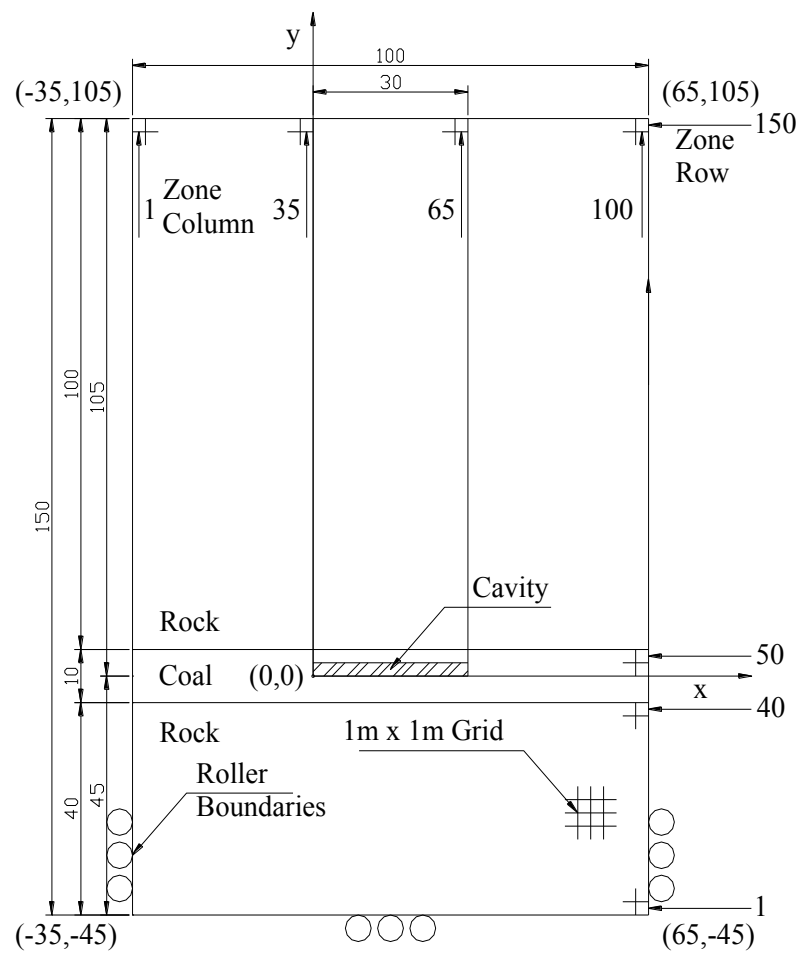

Figure 2 - Model geometry in FLAC.

- Surface load and initial stresses

As previously stated, the specific site of interest is free of any particularly heavy infrastructure on the surface. Only pipe networks are assumed to be located on the surface. If a $200 \mathrm{~kg} / \mathrm{m}^{2}$ surface load is assumed, approximately a $2000 \mathrm{~Pa}$ vertical stress is applied on surface, which due to the depth of process its effect is small and it has been ignored to reduce the calculation time (FLAC, 2008).

On the other hand, rock layers exist in stressed state prior any excavation. By setting initial conditions in the FLAC grid this in-situ state is reproduced. And thus, gravity and in-situ horizontal stresses are incorporated into the model.

Gravitational loading is specified by setting the magnitude of gravitational acceleration to 9.81 $\mathrm{m} / \mathrm{sec}^{2}$. The model is allowed to undergo deformations, and this is being done by activating the Large-Strain option. The equilibrium state in model is achieved when the maximum ratio of the unbalanced mechanical force to the applied mechanical force for all grid points drops below 0.001 by default, in order to reduce the running time this ratio has been increased to 0.01 . This will also reduce the number of steps taken in thermal calculation to reach equilibrium.

- Material properties

The Mohr-Coulomb model is the conventional model used to represent shear failure in soils and rocks. The failure envelope for this model corresponds to a Mohr-Coulomb criterion (shear yield function or $\mathrm{f}_{\mathrm{s}}$ ) with tension cutoff (tensile yield function or $\mathrm{f}_{\mathrm{t}}$ ), where $\mathrm{f}_{\mathrm{s}}$ is friction angle, $\mathrm{c}$ cohesion, $t$ tensile strength and $\sigma_{1}, \sigma_{2}$ and $\sigma_{3}$ are the principle stresses (Equation 1 and 2):

Equation 1 - Formula for Friction Angle

$$
\mathrm{fs}=\sigma 1-\sigma 3 \mathrm{~N} \varphi+2 \mathrm{c} \sqrt{\mathrm{N} \varphi} \quad \mathrm{N} \varphi=\frac{1+\sin \varphi}{1-\sin \varphi}
$$


Equation 2 - Formula for Tensile Strength

$\mathrm{t}=\sigma 1-\sigma 3 \quad \sigma 1 \leq \sigma 2 \leq \sigma 3$

In Figure 1 it is evident that there are several types of rock formation in each age layer at the DCD site. The thermal properties of these formations were calculated on the basis of their thickness and material properties. For thermal options, isotropic conductivity has been assumed for the model, in order to verify the functionality of thermal-mechanical coupling. In what concerns the mechanical properties of the geologic formations, the properties used have been obtained through experimental testing carried out by Overgas. The respective values are presented in Tables 1 and 2 respectively. In this model, the initial rock and coal temperature has been assumed to be $10^{\circ} \mathrm{C}$ and the temperature at the burn front is assumed to be $1000^{\circ} \mathrm{C}$.

\subsubsection{Simulation}

The process includes 3 runs. In the first run, the geology of the model is allowed to reach equilibrium under gravity, which due to initial stresses defined this would happen instantaneously (after 2 steps). Two series of codes are defined in this model, the first one models excavation by a loop, which sets the constitutive model for excavated zones to null. The second code incorporates the burn with excavation, by moving a $1000^{\circ} \mathrm{C}$ temperature front along the excavation (Yang, 2004). The initial temperature of strata is $10^{\circ} \mathrm{C}$ and the heat is allowed to conduct through strata. The burn speed assumed for this model is 1 meter/day. Excavation and Burn runs have been saved at every 5 meters of excavation in order to study the developments of failed zones, temperature contour distributions, surface and cavity's roof displacements.

Table 1 - Mechanical properties of Geologic Formations.

\begin{tabular}{|c|c|c|c|c|c|c|}
\hline Geologic age & \multicolumn{2}{|c|}{ Density $\rho\left(K g / \mathbf{m}^{3}\right)$} & \multicolumn{2}{|c|}{$\begin{array}{c}\text { Elastic modulus } E \\
(\mathrm{GPa})\end{array}$} & \multicolumn{2}{|c|}{$\begin{array}{c}\text { Poisson's ratio } \\
v\end{array}$} \\
\hline \multirow{3}{*}{ Neogene $(\mathrm{N})$} & $0{ }^{\circ} \mathrm{C}$ & 2440 & $0^{\circ} \mathrm{C}$ & 55.28 & $00^{\circ} \mathrm{C}$ & 0.274 \\
\hline & $1000^{\circ} \mathrm{C}$ & 2404 & $700^{\circ} \mathrm{C}$ & 18.74 & $700^{\circ} \mathrm{C}$ & 0.274 \\
\hline & & & $1000^{\circ} \mathrm{C}$ & 14.27 & $1000^{\circ} \mathrm{C}$ & 0.274 \\
\hline \multirow{3}{*}{ Paleogene (Pg) } & $0{ }^{\circ} \mathrm{C}$ & 2471 & $0^{\circ} \mathrm{C}$ & 40.1 & $0^{\circ} \mathrm{C}$ & 0.265 \\
\hline & $1000^{\circ} \mathrm{C}$ & 2467 & $700^{\circ} \mathrm{C}$ & 11.5 & $1000^{\circ} \mathrm{C}$ & 0.265 \\
\hline & & & $1000^{\circ} \mathrm{C}$ & 10.2 & & \\
\hline \multirow{3}{*}{$\begin{array}{l}\text { K - J } \\
\text { (Lower Cretacerous- } \\
\text { Upper Jurassic) }\end{array}$} & $0^{\circ} \mathrm{C}$ & 2350 & $0^{\circ} \mathrm{C}$ & 80 & $0{ }^{\circ} \mathrm{C}$ & 0.31 \\
\hline & $1000^{\circ} \mathrm{C}$ & 2256 & $700^{\circ} \mathrm{C}$ & 35.2 & $1000^{\circ} \mathrm{C}$ & 0.31 \\
\hline & & & $1000^{\circ} \mathrm{C}$ & 24 & & \\
\hline \multirow[t]{3}{*}{ Triassic (T1) } & $0{ }^{\circ} \mathrm{C}$ & 2350 & $0^{\circ} \mathrm{C}$ & 80 & $0{ }^{\circ} \mathrm{C}$ & 0.31 \\
\hline & $1000^{\circ} \mathrm{C}$ & 2256 & $700^{\circ} \mathrm{C}$ & 35.2 & $1000^{\circ} \mathrm{C}$ & 0.31 \\
\hline & & & $1000^{\circ} \mathrm{C}$ & 24 & & \\
\hline \multirow{3}{*}{ Carboniferous ( C) } & $0^{\circ} \mathrm{C}$ & 2465 & $0^{\circ} \mathrm{C}$ & 29.9 & $0{ }^{\circ} \mathrm{C}$ & 0.225 \\
\hline & $1000^{\circ} \mathrm{C}$ & 2465 & $700^{\circ} \mathrm{C}$ & 11.88 & $1000^{\circ} \mathrm{C}$ & 0.225 \\
\hline & & & $1000^{\circ} \mathrm{C}$ & 10.90 & & \\
\hline \multirow{3}{*}{ Devonian(D) } & $0{ }^{\circ} \mathrm{C}$ & 2350 & $0^{\circ} \mathrm{C}$ & 80 & $0{ }^{\circ} \mathrm{C}$ & 0.31 \\
\hline & $1000^{\circ} \mathrm{C}$ & 2256 & $700^{\circ} \mathrm{C}$ & 35.2 & $1000^{\circ} \mathrm{C}$ & 0.31 \\
\hline & & & $1000^{\circ} \mathrm{C}$ & 24 & & \\
\hline
\end{tabular}


Table 2 - Thermal Properties of Geologic Formations.

\begin{tabular}{|c|c|c|c|c|c|c|}
\hline Age & $\begin{array}{l}\text { Specific } \mathrm{h} \\
c\left(\mathrm{~J} /\left(\mathrm{Kg}{ }^{\circ}\right.\right.\end{array}$ & & $\begin{array}{l}\text { Thermal } \\
\text { tivity } \\
k(\mathbf{W} /(\mathbf{m} .\end{array}$ & iduc- & $\begin{array}{l}\text { Thermal e } \\
\text { sion } \\
\alpha\left(/^{\circ} \mathrm{C}\right)(1 \mathrm{e}\end{array}$ & \\
\hline \multirow{4}{*}{ Neogene $(\mathrm{N})$} & $0^{\circ} \mathrm{C}$ & 1152 & $0^{\circ} \mathrm{C}$ & 1.84 & $0^{\circ} \mathrm{C}$ & $\overline{8.4}$ \\
\hline & $1000^{\circ} \mathrm{C}$ & 1664 & $600^{\circ} \mathrm{C}$ & 0.368 & $100^{\circ} \mathrm{C}$ & 8.4 \\
\hline & & & $1000^{\circ} \mathrm{C}$ & 0.368 & $500^{\circ} \mathrm{C}$ & 1.68 \\
\hline & & & & & $1000^{\circ} \mathrm{C}$ & 1.15 \\
\hline \multirow{4}{*}{ Paleogene (Pg) } & $0^{\circ} \mathrm{C}$ & 1007 & $0^{\circ} \mathrm{C}$ & 1.96 & $0^{\circ} \mathrm{C}$ & 9.18 \\
\hline & $1000^{\circ} \mathrm{C}$ & 1343.5 & $600^{\circ} \mathrm{C}$ & 0.483 & $100^{\circ} \mathrm{C}$ & 9.18 \\
\hline & & & $1000^{\circ} \mathrm{C}$ & 0.418 & $500^{\circ} \mathrm{C}$ & 1.2 \\
\hline & & & & & $1000^{\circ} \mathrm{C}$ & 0.87 \\
\hline \multirow{4}{*}{$\begin{array}{l}\text { K - J } \\
\text { (Lower Cretacerous- } \\
\text { Upper Jurassic) }\end{array}$} & $0^{\circ} \mathrm{C}$ & 1530 & $0^{\circ} \mathrm{C}$ & 1.6 & $0^{\circ} \mathrm{C}$ & 6 \\
\hline & $1000^{\circ} \mathrm{C}$ & 2540 & $600^{\circ} \mathrm{C}$ & 0.32 & $100^{\circ} \mathrm{C}$ & 6 \\
\hline & & & $1000^{\circ} \mathrm{C}$ & 0.32 & $500{ }^{\circ} \mathrm{C}$ & 3.6 \\
\hline & & & & & $1000^{\circ} \mathrm{C}$ & 2.28 \\
\hline \multirow{4}{*}{ Triassic (T1) } & $0^{\circ} \mathrm{C}$ & 1530 & $0^{\circ} \mathrm{C}$ & $\overline{1.6}$ & $0{ }^{\circ} \mathrm{C}$ & $\overline{6}$ \\
\hline & $1000^{\circ} \mathrm{C}$ & 2540 & $600^{\circ} \mathrm{C}$ & 0.32 & $100^{\circ} \mathrm{C}$ & 6 \\
\hline & & & $1000^{\circ} \mathrm{C}$ & 0.32 & $500{ }^{\circ} \mathrm{C}$ & 3.6 \\
\hline & & & & & $1000^{\circ} \mathrm{C}$ & 2.28 \\
\hline \multirow{4}{*}{ Carboniferous ( C) } & $0^{\circ} \mathrm{C}$ & 1070 & $0^{\circ} \mathrm{C}$ & 2 & $0^{\circ} \mathrm{C}$ & 8.4 \\
\hline & $1000^{\circ} \mathrm{C}$ & 1532 & $600^{\circ} \mathrm{C}$ & 0.9 & $100^{\circ} \mathrm{C}$ & 8.4 \\
\hline & & & $1000^{\circ} \mathrm{C}$ & 0.5 & $500{ }^{\circ} \mathrm{C}$ & 2.24 \\
\hline & & & & & $1000^{\circ} \mathrm{C}$ & 1.49 \\
\hline \multirow{4}{*}{ Devonian(D) } & $0^{\circ} \mathrm{C}$ & 1530 & $0^{\circ} \mathrm{C}$ & 1.6 & $0^{\circ} \mathrm{C}$ & $\overline{6}$ \\
\hline & $1000^{\circ} \mathrm{C}$ & 2540 & $600^{\circ} \mathrm{C}$ & 0.32 & $100^{\circ} \mathrm{C}$ & 6 \\
\hline & & & & & $500{ }^{\circ} \mathrm{C}$ & 3.6 \\
\hline & & & $1000^{\circ} \mathrm{C}$ & 0.32 & $1000^{\circ} \mathrm{C}$ & 2.28 \\
\hline
\end{tabular}

\section{Enhanced FLAC Model of the DCD Area}

For the enhanced model, a $135 \times 275$ mesh has been used, thus resulting in a model consisting of 37125 grids. A finer mesh structure has been used for the area around the coal seam, where the gasification takes place so that more accurate results can be obtained. The mechanical and thermal properties of the different geological layers, has been assigned in accordance with the relative results of experimental studies on Dobrudzha coal samples (Table 1). The grid has the left- and right-hand sides fixed to the horizontal direction, and the bottom boundary fixed in the vertical direction. The temperature of the model is assumed to be initially $10^{\circ} \mathrm{C}$ and reaches a maximum value of $800^{\circ} \mathrm{C}$. The thermal model used to simulate the heat transfer along the different geologic materials is the "Isotropic Heat Conduction" model.

\subsection{Sensitivity Analysis}

Underground Coal Gasification process is believed to be directly linked to hazards due to the surface subsidence. In the case of the DCD though, due to the large depth of the coal seam, the properties of the overburden rock and the lack of surface infrastructure, the main potential hazards will be developed due to the complex geology of the area and more specifically the presence of numerous faults which are intersecting the whole DCD area. Faults and the area around can potentially be source of instabilities as well as a path of possible leakage of the product gas, 


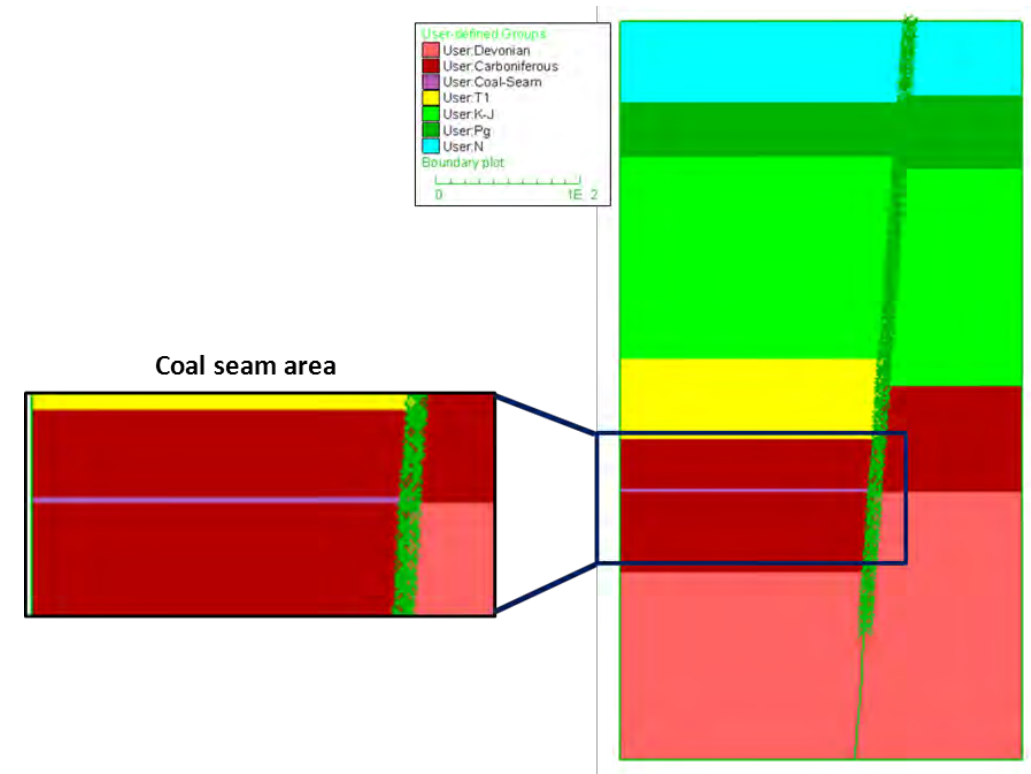

Figure 3 - Enhanced FLAC model.

especially in the case of their reactivation. As such, the following simulation process is a Sensitivity Analysis, in an attempt to decide the degree of UCG impact to the nearby faults and thus the minimum allowed distance between the UCG tunnel and the faults. More specifically, several runs have been carried out simulating the UCG process, maintaining the majority of the model properties constant and varying the normal stiffness and shear stiffness values assigned to the fault.

The gasification process is assumed to begin $100 \mathrm{~m}$ away from the left model boundary-in order to avoid any boundary effects-and extends laterally for $400 \mathrm{~m}$ to the direction of the fault. The tunnel developed due to the coal gasification finishes $100 \mathrm{~m}$ away from the fault zone.

In order to acquire a better understanding of the simulation process, how this proceeds and how the several mechanical and thermal effects develop during the gasification process, several measurements have been acquired during the gasification process within equal timesteps, in order to gain a good understanding of the model state throughout the gasification process. More specifically, the gasification process has been divided into 8 steps, during which equal seam lengths have been gasified, and the model state has been saved at the end of each step.

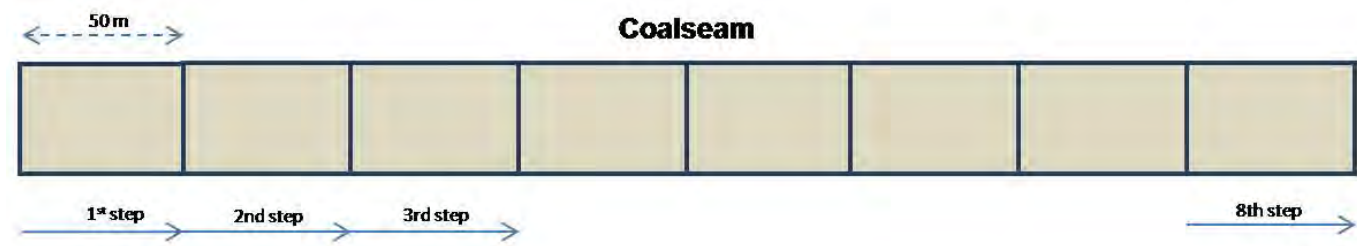

Figure 4 - Excavation Steps.

In the basecase run the fault included in the model has been characterized as glued i.e. no slip or opening is allowed between the two interfaces, but elastic displacement still occurs. The normal and shear stiffness are 0.4 and 1.0 respectively. In the first set of runs the shear stiffness has been kept constant and the value of normal stiffness varies between 0.3 and 0.6. In the second set of runs the normal stiffness has been kept constant at 0.4 and the shear stiffness varies between 0.6 and 0.9 . 
Table 3 - Simulation and Fault Properties.

\begin{tabular}{|l|c|c|}
\hline \multicolumn{1}{|c|}{ Basecase } & Normal stiffness (N/m) & Shear stiffness (N/m) \\
\hline $\mathbf{1}^{\text {St }}$ set of Runs & 0.4 & 1.0 \\
\hline Case_1 & 0.3 & 1.0 \\
\hline Case_2 & 0.2 & 1.0 \\
\hline Case_3 & 0.5 & 1.0 \\
\hline Case_4 & 0.6 & 1.0 \\
\hline $2^{\text {nd }}$ set of Runs & \multicolumn{2}{|}{} \\
\hline Case_a & 0.4 & 0.9 \\
\hline Case_b & 0.4 & 0.8 \\
\hline Case_c & 0.4 & 0.7 \\
\hline Case_d & 0.4 & 0.6 \\
\hline
\end{tabular}

\subsubsection{Mechanical Effects- Stress Distribution}

In the first set of runs, the shear stiffness has been kept constant and the normal stiffness varies according to the values indicated in the aforementioned table. During the first steps of the gasification process one can see the stresses and fault zones developing around the cavity to an extent of approximately $100 \mathrm{~m}$ above and below the seam. The stress zones develop approximately in the same way for all the cases of this set of runs, although, one can observe little difference in the timing of the stress development. More specifically the lower the value of the normal stiffness the quicker the stress zones begin to develop around the cavity and to the vertical direction. This difference in the timing though is so small, that cannot be easily depicted

The same applies for the two cases in which the normal stiffness has been assumed 0.5 and 0.6 $\mathrm{N} / \mathrm{m}$ respectively. Again, the stress distribution presents a slight delay in the development, though finally the overall area influenced by the process remains more or less the same. In Figure 5, the stress distribution and failed zones are presented during the $4^{\text {th }}$ and the $6^{\text {th }}$ step of the excavation process.

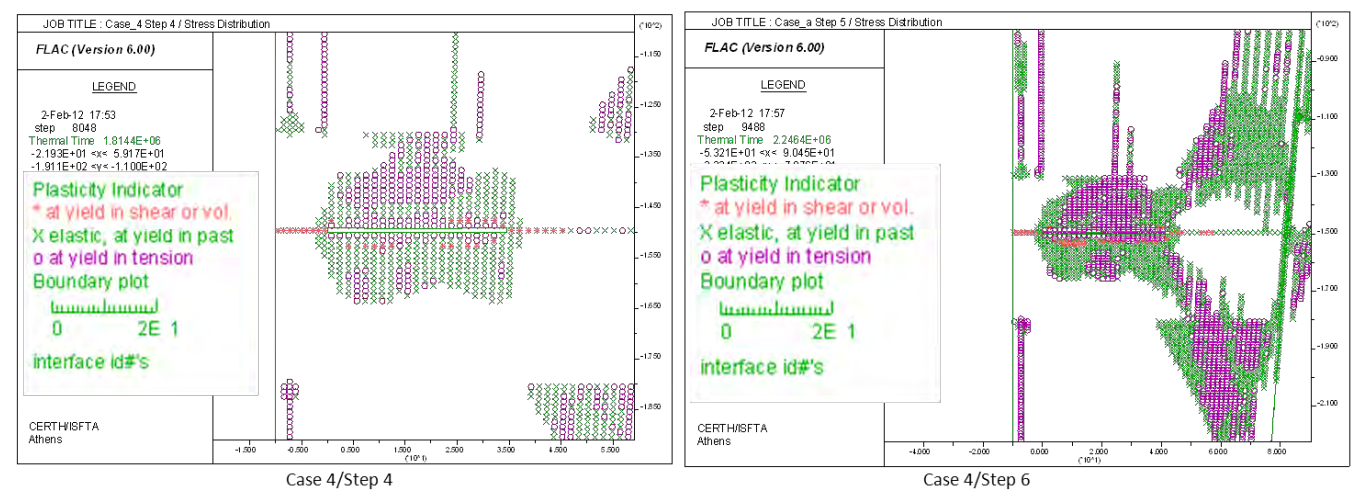

Figure 5 - Stress Distribution.

In the $2^{\text {nd }}$ set of runs, it is observed that the different values of shear and normal stiffness have little effect at the timing of the stress distribution expansion towards the fault, as well as the shape of the failed zones and the fault zone behavior.

Initially the fault zones develop to an extent of approximately $100 \mathrm{~m}$ above and below the seam length excavated. As the gasification proceeds towards the fault, the stress distribution expands further towards the fault and the interfaces between the other geological layers present in the mod-

XLVII, No 3 - 2097 
el. What can be concluded from the simulation runs is that the end of the gasification tunnel should be placed at least $400 \mathrm{~m}$ away from the fault zone. As it is obvious in Figure 5 after step 5 i.e. $350 \mathrm{~m}$ of gasification tunnel, there is a major failed zone expansion towards the fault.

The temperature effects extend to a distance of approximately $50 \mathrm{~m}$ above and below the gasification channel (Figure 6). It is also worth noting that the lateral temperature effect is even smaller due to the low thermal conductivity of the coal, and so the temperature effects extend laterally approximately $20 \mathrm{~m}$, As such the presence of the fault is not affected at all by the temperature changes around the gasification channel. A safe distance of approximately $80 \mathrm{~m}$ even after the last step of the gasification process is maintained, which has already been excluded from the process due to the intense mechanical influence of the gasification channel to the fault.

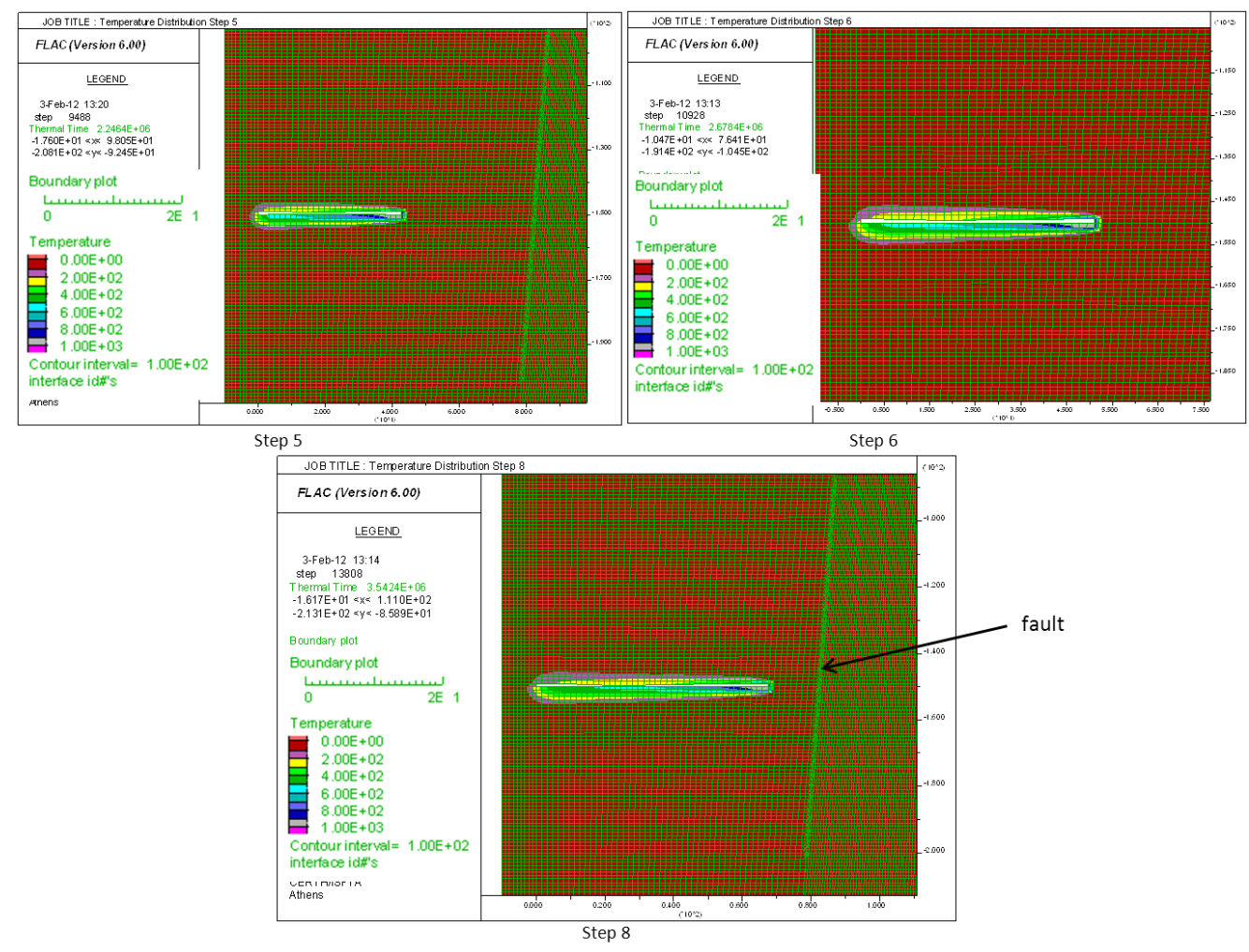

Figure 6 - Temperature Distribution.

Moreover and since the thermal properties of the geological layers have not been altered throughout these two sets of simulation runs, the temperature distribution remains the same throughout the two sets of runs and so further results of the rest of the cases are not presented within this paper.

\section{Discussions}

In order to acquire a clear and well-rounded understanding of the process, the development of the gasification has been divided in three distinct stages. The first one represents the state of cavity and the surrounding rock at the beginning of the gasification/excavation process. The second stage presents the process status mid-ways the gasification/excavation process and the third and final stage presents the geomechanical status of the area at the end of the gasification/excavation process. Under this scheme the results of the process simulation will be presented.

Figure 6 presents the temperature distribution around the cavity, during the gasification process. Although accurate quantitative conclusions cannot be drawn in this case, these profiles can provide 
a qualitative approach of the temperature distribution during the gasification process. With respect to the thermal time passed, the maximum temperature reached during the gasification process is $1000{ }^{\circ} \mathrm{C}$, which by the end of this process has dropped to $600{ }^{\circ} \mathrm{C}$ at the end of excavation length, temperature contours are redistributed more evenly and the distance between contours has increased. Another point observed at different stages is that, the heat has only penetrated a depth of 2 meter into cavity's vicinity.

New cavity shape is formed by fall of roof elements that fail in tension, which are next to the existing cavity's perimeter. The cavity shape changes by inclusion of burn as well as the overall area of failed zones especially on the two ends of the excavation length. Different snapshots clearly illustrate the development of a vertical crack in the beginning of excavation length, which propagates upwards as the excavation proceeds in the burn model. The effect of temperature is a vital parameter for calculation of both displacements and stresses developed.

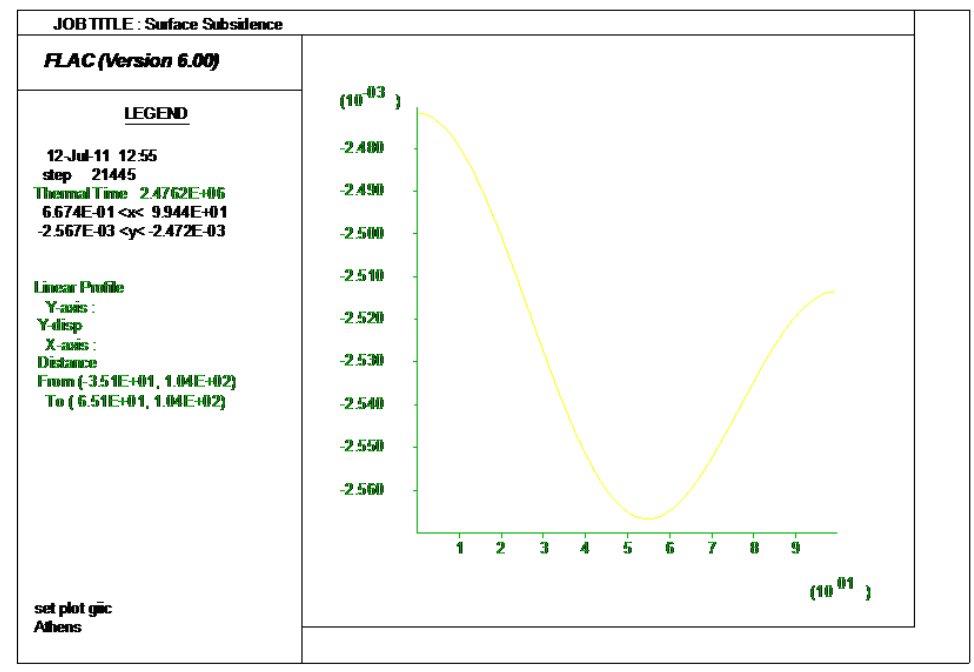

Figure 7 - Surface Subsidence.

The surface subsidence profile (Figure 7) has an inverted bell shape thus, indicating that the maximum subsidence occurs in the middle of excavation length. There is also a slight asymmetry in the surface subsidence, which is possibly the effect of the asymmetric cavity development. It is noted that cohesion and tension are measured in pascals $(\mathrm{Pa})$ and friction and dilation angles in degrees $\left(^{\circ}\right)$.

\section{Conclusions}

After the analysis of the aforementioned results, it can be concluded that

- The stress zones present the same pattern, and extend approximately $100 \mathrm{~m}$ above and below the fault, regardless of the fault properties. Moreover, it is worth noting that the pattern of the failed zones is the same regardless of changes in the fault properties, though there are changes at the rate at which the failure begins and proceeds.

- The lower the value of the normal stiffness, the quicker the stress development

- It is concluded that the presence of the fault in the area were the gasification process takes place is of critical importance. The fault itself along with the surrounding area which is already mechanically disrupted. Moreover, once the first zones fail, the failure pattern extend to the direction of the fault, thus making it clear the presence of the fault influences the geomechanical behaviour of the area. The gasification channel should be placed at least $400 \mathrm{~m}$ away from the fault in order to avoid any instability issues

XLVII. No 3 - 2099 
- The temperature effects extend to a distance of approximately $50 \mathrm{~m}$ above and below the gasification channel. As such the effect of mechanical failure due to high temperature is dominating a relatively limited area. This is mainly attributed to the low thermal conductivity of coal and the surrounding rocks.

\section{Acknowledgements}

We acknowledge the "UCG- $\mathrm{CO}_{2}$ Storage" project funded under the RFCS Framework Programme and the partners.

\section{References}

Burton E., Friedmann J. and Upadhye R. 2006. Best Practices in Underground Coal Gasification. Contract W-7405-Eng-48; Lawrence Livermore National Laboratory: Livermore, CA.

Chappell R. S. and Wilks I.H.C. 1983. A theory for the underground gasification of deep coal by the linked vertical well method, Stanhope Bretby-Mining Research and Development Establishment.

Coal Statistics 2012. World Coal Association. Available online at: http://www.worldcoal.org/resources/coal-statistics/

FLAC 6.0 Theory and Background 2008. Itasca Consulting Group, Minneapolis, Minnesota, USA.

FLAC 6.0 User's Guide, 2008. Itasca Consulting Group, Minneapolis, Minnesota, USA.

Harloff G. J., 1983. Underground Coal Gasification Cavity Growth Model, J. Energy, 7, 410-415. Overgas Inc, 2011. Geological and Geomechanical data for the Dobrudzha coal field area.

Yang L. 2004. Study on the Model Experiment and Numerical Simulation for Underground Coal Gasification, Fuel, 83, 573-584. 